\title{
What Can Influence the Quality of International Collaborative Publications: A Case Study of Humanities and Social Sciences International Collaboration in China's Double First-Class Project Universities
}

\author{
Zhe Cheng ${ }^{1,2}\left(\mathbb{D}\right.$, Xingfu Lu ${ }^{2, *}$, Xiong Xiong ${ }^{1, *}$ and Chuanyi Wang ${ }^{2, *}$ \\ 1 Institute of Education, Hubei University, Wuhan 430000, China; chengz19@mails.tsinghua.edu.cn \\ 2 Institute of Education, Tsinghua University, Beijing 100084, China \\ * Correspondence: luxf19@mails.tsinghua.edu.cn (X.L.); xiongxiong0804@hubu.edu.cn (X.X.); \\ wcy1985@tsinghua.edu.cn (C.W.)
}

\section{check for}

updates

Citation: Cheng, Zhe, Xingfu Lu, Xiong Xiong, and Chuanyi Wang. 2021. What Can Influence the Quality of International Collaborative Publications: A Case Study of Humanities and Social Sciences International Collaboration in China's Double First-Class Project

Universities. Social Sciences 10: 109 https://doi.org/10.3390/socsci10030109

Academic Editor: Nigel Parton

Received: 23 February 2021

Accepted: 17 March 2021

Published: 21 March 2021

Publisher's Note: MDPI stays neutral with regard to jurisdictional claims in published maps and institutional affiliations.

Copyright: (c) 2021 by the authors. Licensee MDPI, Basel, Switzerland. This article is an open access article distributed under the terms and conditions of the Creative Commons Attribution (CC BY) license (https:// creativecommons.org/licenses/by/ $4.0 /)$.

\begin{abstract}
International collaboration is one of the effective ways to enhance the impact of scientific research papers. In this research, international research collaboration papers published by world-class universities in the field of humanities and social sciences from 2015 to 2019 were selected as the research object, and the effective enhancement of the impact of international research collaboration papers was found to not be dependent on expanding the scale of international research collaboration, but rather on selecting researchers with different international backgrounds and from high-level institutions for collaboration. It was also discovered that, in the field of humanities and social sciences, despite a relatively low proportion of international research collaboration papers being led by Chinese scholars, the Chinese research is characterized by a higher impact compared with the research led by non-Chinese scholars. In light of this, a series of proactive measures should be taken by China's world-class universities, such as actively participating in and initiating international collaboration, selecting high-level research collaborators, and attracting scholars from different countries to engage in research collaboration in the field of humanities and social sciences.
\end{abstract}

Keywords: international collaboration; scientific research impact; impact factors

\section{Introduction}

Scientific research collaboration is one of the effective ways to enhance the innovation and impact of scientific research (Katz and Martin 1997), and high-level researchers often boast of an extensive network of international partnerships (Abramo et al. 2011a). According to the "Report on the Status of China's International collaboration in Science and Technology" released by the National Center for Science and Technology Evaluation (NCSTE) in 2017, China has reached the third place (after the USA and UK) in the world in terms of the scale of its international collaboration papers, with collaborators distributed in 188 countries and regions, basically covering entire the global academic network. In the process of China's higher education shifting from scale expansion to qualitative development, the scale of international collaboration papers has risen sharply, requiring researchers to show solicitude for the quality of international scientific research collaboration, explore the factors that enhance the impact of international scientific research collaboration, and provide references for China to build world-class universities and promote an innovation-driven development strategy.

Since the beginning of the 21st century, humanities and social sciences have played an important role as bridges and links in international exchanges and global governance. It was pointed out that social science covers a variety of complex issues and disciplines, and social science is of great significance not only to research and teaching, but also to government policy making (Wood et al. 2007). Under the background of globalization, 
international collaboration in social sciences is conducive to the participation of all countries in the process of global governance, and in-depth collaboration in social sciences by researchers from all over the world contributes to the clarification and analysis of the manifestations of global issues in countries around the world, thereby providing a factual basis for better formulation of global governance policies. Similar to social sciences, the humanities also play an important role in international cultural exchanges. As early as 2007, the European Commission proposed at the conference "Social Sciences and Humanities in Europe: New Challenges and New Opportunities" that the humanities can contribute to cross-cultural exchanges and eloquent skills for this diverse world, and promote global exchanges (Parker 2007). The current exchange activities of countries around the world rely more on the valuable information provided by humanities research, aiming to enhance international exchanges and understanding, so that all countries in the world can live together and share prosperity under the concept of community of human destiny. China's international status has been increasing and has a great influence on global affairs, so it is necessary to choose a Chinese high standard university as the research object, which undertake most important international cooperation tasks.

In 2015, Chinese government issued the world first-class universities and world firstclass disciplines project in order to improve the comprehensive strength of higher education in China. Promoting international exchanges and collaboration is one of the five major tasks in the project. World-class universities have played an important role in the development of international collaboration and research. Based on the importance of humanities and social science in international exchanges and collaboration, analysis was carried out on the international scientific research collaboration papers of 42 world-class universities in China, with the purpose of exploring the factors that enhance the impact of international scientific research collaboration papers, and providing a reference for Chinese universities to seek better international research collaborators and carry out higher-level international research collaboration in the field of humanities and social sciences.

\section{Literature Review}

As an important form of reflecting researchers' scientific research output, scientific research papers are a typical embodiment of international scientific research collaboration achievements. Price pointed out that, as human beings enter the era of big science, scientific research collaboration will become a common trend (Price et al. 1982). It is also a common practice for existing research to reflect the impact of international scientific research collaboration based on papers (Ye et al. 2017; Qiu and Zeng 2013). It is generally believed that international collaboration can effectively improve the impact of scientific research papers, but current research usually only analyzes the differences between international collaboration papers and local papers from a comparative perspective.

From the perspective of relevant research with countries as the comparative unit, existing research generally believes that, whether for developed countries or developing countries, the impact of international collaboration papers is higher than that of domestic research papers. According to the conclusion of Italian universities as research objects, the research output and quality of researchers are significantly positively correlated with the degree of international collaboration (Abramo et al. 2011b). In contrast, the conclusion of taking British universities as research objects shows that the average impact of British international collaboration papers is higher than that of national scientific research papers (Adams et al. 2007), while the conclusion of major research output countries as research objects shows that international collaboration can effectively improve the scientific research quality of papers (Lancho-Barrantes et al. 2013). It is unanimously agreed by relevant research based on country comparisons that international collaboration papers are more influential and spread more widely than non-international collaborative papers.

Nevertheless, there are differences in the research conclusions obtained from the relevant research taking disciplines as comparative units. Existing research has found that international collaboration research papers have a higher impact compared with 
international scientific research collaboration papers and non-international scientific research collaboration papers in the fields of chemistry, life sciences, biomedicine, astronomy, etc. (Narin et al. 1991; Bordons et al. 1996; Van Raan 1998; Glänzel and Schubert 2001; Glänzel and Lange 2002; He 2009; Suárez-Balseiro et al. 2009; Puuska et al. 2014). It was, however, found that the research quality of international collaboration papers shows no obvious advantage in the field of finance (Avkiran 1997). Such differences in research conclusions may be attributed to differences in disciplinary characteristics and national research environments.

In addition, some research has been carried out specifically to compare specific institutions, and their conclusions differ significantly. For example, research on top universities in the United States and the European Union found a significant positive relationship between international research collaboration and the quality of papers (Adams et al. 2005; Barjak and Robinson 2008). However, the research with Louis Pasteur University as the analysis object found no evidence that international collaboration contributes to scientific research productivity and impacts (Carayol and Matt 2004).

It can be concluded by combing the previous research and related conclusions that the existing research mainly focuses on the comparison of the impact of international collaboration papers and non-international collaboration papers. Although some research has also explored the impact of international collaboration on scientific research from the perspective of relevance, the research conclusions vary among different institutions and disciplines. It is worth noting that few studies have explored the factors that affect the impact of collaboration papers in this research process, which may be due to the lack of access to vast amounts of data on the author's collaboration background information. Based on the previous research foundation and research limitations, this research was carried out to explore the related factors that affect the international research collaboration papers on the humanities and social sciences in China's world-class universities, and to analyze the impact of the author-related background information obtained by Python crawler technology on international scientific research collaboration papers, so as to better guide the domestic high-level colleges and universities to conduct international research collaboration.

\section{Research Design and Data Acquisition}

\subsection{Research Hypothesis}

In general, a citation is a typical variable which measures the impact of international collaboration research papers (Van Raan 1998). There are also some other indicators developed which intend to reflect the impact of scientific research papers. It is worth noting that there are differences in the conclusions of previous studies using different indicators to measure the impact of scientific research. FWCI (Field-Weighted Citation Impact) is often used in various studies to measure the impact of scientific papers; as a result, the FWCI of papers has a bearing on whether to carry out international collaboration (Leydesdorff et al. 2017), and international collaboration plays a greater role in improving the quality of scientific research publications of young universities (Khor and Yu 2016). However, it was found that scientific collaboration failed in improving the quality of scientific papers in the research of measuring the impact of scientific papers by citations (Roosa and Julia 2005). As more and more problems are exposed in the evaluation of citations, FWCI is commonly incorporated into existing studies to judge the impact of research papers. FWCI reflects the ratio of citations of a paper to citations per paper of the same discipline, year, and type. Compared with citations of a paper, FWCI can be utilized to better control the effect from disciplines and time on citation. Therefore, in this research, FWCI was taken as a dependent variable to characterize the impact of scientific research achievements, so as to measure the impact of international research collaboration papers more accurately.

This research is dedicated to exploring the factors that improve the impact of international scientific research papers, with its key to research design of the determination of relevant independent variables. Despite that few existing researches have explored the causal relationship between the variables and the impact of international collaboration 
papers, a series of factors contributing to the impact of international scientific research collaboration papers have also been reflected in relevant studies.

First of all, from the perspective of scholars, the academic level of researchers is the primary factor affecting the impact of scientific research papers. Previous studies have found that researchers involved in international collaboration generally have high academic achievements and status (Kwiek 2020), personal academic impact is an important variable affecting international collaboration (Payumo et al. 2017), personal research performance has a positive impact on the degree of international collaboration of scientists (Abramo et al. 2011b), and international collaboration can effectively promote the improvement of personal academic impact (Yao et al. 2013). International collaboration with high-level researchers can often improve the popularity of research. In the process of international collaboration research, the academic achievements of participants are also an important factor to promote the completion of international collaboration (Jeong et al. 2011). Therefore, in many studies, researchers' research performance, academic achievements, and academic impact are regarded as important factors affecting international collaboration (Abramo et al. 2011b). The H-index, as a common indicator to measure the impact of scientific researchers, can not only reflect the academic output of scientific researchers, but also reflect their overall impact. Therefore, the H-index was utilized as an important indicator to measure the ability of researchers in this research.

Furthermore, with the deepening of internationalization, factors affecting the effectiveness of international collaboration include the academic impact of researchers, while the number of people participating in research is also an important variable affecting the impact of scientific research. Scholars with diverse knowledge backgrounds are capable of pooling wisdom, learning from each other's strengths, making up for research deficiencies, and improving the quality of research. Numerous studies have shown that there is a positive relationship between the size of researchers involved in collaboration and the impact of research. Previous studies have found that in China, the scale of a research team is positively correlated with the impact of research, and the smaller the scale of collaboration, the lower the impact (Quan et al. 2019). The results of a Norwegian international collaboration analysis also show that the size of the research team has a positive effect on both the quality and quantity of research (Kyvik and Reymert 2017). However, different researchers have obtained different results in different research fields. It has been found that in the field of educational technology, there is a significant positive correlation between the number of authors of international collaboration and the number of papers cited (Guo et al. 2015), but the quality of international collaboration papers in the field of humanities has no obvious advantage (Puuska et al. 2014). Based on the discussion on the relationship between research team size, research team level and paper impact in previous studies, the following hypotheses were made in this research:

Hypothesis 1 (H1). In the field of humanities and social sciences, the higher the total H index of participants in international collaboration papers, the greater the impact of papers on scientific research.

Hypothesis 2 (H2). In the field of humanities and social sciences, the greater the number of participants in international collaboration papers, the greater the impact of papers on scientific research.

In addition to focusing on the information characteristics of the authors themselves, previous studies have shown that the number of units involved in scientific research papers is also an important factor affecting the quality of scientific research papers. Researchers from different institutions are often able to complement each other with their discipline background knowledge and research skills, thus achieving scientific research innovation. According to the research on papers published by Harvard University, publications with more institutional participation tend to be cited more frequently (Gazni and Didegah 2011). In addition, scientific research impact can be effectively improved by the diversity of the team, but such a diversity needs to be moderate because maximum diversity does not lead to maximum performance (Barjak and Robinson 2008). It is worth noting that 
although different research backgrounds and cultures can be reflected by team diversity, the degree to which different indicators reflect cultural diversity varies. Compared with different institutions, differences in background and knowledge between collaborators can be reflected by the number of countries involved. It has been pointed out by some studies that the number of countries participating in international collaboration is an important factor affecting international collaboration (Prakasan et al. 2014). The more countries participating in international collaboration, the greater the impact (Guerrero Bote et al. 2013), although the high citation brought by such multinational collaboration may be caused by audience effect (Wagner et al. 2019). Based on the existing research conclusions, the following hypotheses are made in this research:

Hypothesis 3 (H3). In the field of humanities and social sciences, the more institutions are involved in international collaboration scientific research, the greater the impact of papers on scientific research.

Hypothesis 4 (H4). In the field of humanities and social sciences, the more countries are involved in international collaboration research, the greater the impact of papers on scientific research.

In addition to considering the quantitative information in the institutional background of authors participating in international scientific research collaboration, the level of information reflected by their institutional background should also be taken into account. It has been pointed out that the establishment of international collaboration can be affected by the research resources owned by the collaborators (Chang and Huang 2016), while the mode of international collaboration will be affected by the academic excellence, technological development level, as well as external financial incentives of cooperative institutions (Jeong et al. 2011). World-class universities tend to have abundant research resources and high-level research teams, so the number of the world's top 100 universities which come from the Shanghai Ranking List 2020 participating in international research collaboration was taken as an independent variable in this research. It should be noted that the input of scientific research resources in universities has a bearing on the comprehensive strength of the country where the universities are located. Previous studies have found that developing countries or small countries can enhance the impact of their scientific research collaboration by conducting scientific research with developed countries (Chinchilla-Rodríguez et al. 2012). Such scientific and technological collaboration with countries with disparate economic and technological levels can bring better citation benefits (Hsiehchen et al. 2018), and collaboration with developed countries like the United States can effectively increase the impact of scientific research (Sud and Thelwall 2016). Research also shows that the size of R\&D investment is an important variable affecting the impact of scientific research output, and in social science research, collaboration with countries with high R\&D investment has the greatest benefits (Bordons et al. 2015). Developed countries tend to have higher R\&D investment, so the research hypothesis was put forward as follows:

Hypothesis 5 (H5). In the field of humanities and social sciences, the more high-level universities (the top 100 in the world) participate in international collaboration, the higher the impact of papers on scientific research.

Hypothesis 6 (H6). In the field of humanities and social sciences, the more institutions from developed countries participate in international collaboration, the higher the impact of papers on scientific research.

It should be noted that although international collaboration plays an obvious role in promoting the impact of scientific research, the contributions of authors from different institutions are often different in the process of international collaboration. Studies have pointed out that if non-native scholars act as correspondent authors, it will help to improve 
the citation rate of research (Nguyen et al. 2017); countries with less resources have greater impacts on scientific research when they are not in a leading position in research (ChinchillaRodríguez et al. 2019). This research was carried out to explore the influencing factors of international scientific research paper collaboration in the field of humanities and social sciences, where the position and contribution of participating institutions in international research collaboration were reflected in terms of whether they were the first completion unit. For this reason, in this research, whether a world-class university is the first publishing institution is taken as a control variable that affects the level of international collaboration in humanities and social science research in China.

\subsection{Data Samples}

Scopus is one of the most popular databases in the world. It includes more than 75 million records and contains most of the articles which are collaborated on by international scholars. As international collaboration papers are usually written in English, the database contains most of the collaboration research papers. Based on the Elsevier Scopus database, the following information was summarized in this research: the citations, FWCI, and the sum of the $\mathrm{H}$ index of the paper co-authors for each international collaboration paper published by 42 China's world-class universities in the field of humanities and social sciences from 2015 to 2019, as well as the number of the top 100 universities in the institutions where the authors belong to, the scale of the paper team, the number of countries involved in the paper, the number of developed countries involved in the paper, the number of institutions involved in the paper, and whether the paper belongs to the first author in China's "double first-class" universities; a total of 13,331 papers in the field of humanities and social sciences were obtained. The data acquisition method is shown in Table 1 below.

Table 1. Data acquisition and calculation method.

\begin{tabular}{cc}
\hline Data Variable & Data Acquisition Method \\
\hline Citations & Direct extraction \\
\hline Paper FWCI & Direct extraction \\
\hline Sum of the author's H index & $\begin{array}{c}\text { Relevant authors of this paper were screened } \\
\text { and their H indexes were summed up }\end{array}$ \\
\hline $\begin{array}{c}\text { Number of top 100 universities in the } \\
\text { international rankings of affiliated institutions }\end{array}$ & $\begin{array}{c}\text { International institutions were screened to } \\
\text { count the number of top 100 universities } \\
\text { among them }\end{array}$ \\
\hline Number of authors & Count the number of authors \\
\hline $\begin{array}{c}\text { Number of countries involved in the paper } \\
\text { Number of developed countries involved in } \\
\text { the paper }\end{array}$ & $\begin{array}{c}\text { Count the number of countries covered by } \\
\text { the authors }\end{array}$ \\
\hline $\begin{array}{c}\text { Number of institutions involved in the paper } \\
\text { covered by the authors }\end{array}$ \\
\hline $\begin{array}{c}\text { Whether China's world-class universities are } \\
\text { the leading units or not }\end{array}$ & $\begin{array}{c}\text { Calculate the number of institutions covered } \\
\text { by the authors }\end{array}$ \\
\hline
\end{tabular}

\subsection{Model Design}

Based on the research hypothesis, the explanatory variables of this research are the citations and FWCI of papers, and the independent variables are the total $\mathrm{H}$ index of authors, the number of authors, the number of institutions involved, the number of highlevel institutions involved, the number of cooperative countries involved and the number of developed countries involved. The model equation constructed according to the research hypothesis is as follows: 


$$
\text { FWCI }=\alpha_{1}+\beta_{1} \times X_{n}+\beta_{2} \times \text { Control }+\theta_{i}
$$

where $\alpha$ and $\beta$ represent coefficients of constant term and explanatory variable, respectively, Control indicates the control variable and $\theta$ means the random error term.

Since all variables in this research are continuous variables, the ordinary least squares (OLS) method was used to estimate the coefficients of Equation (1). At the same time, the literature of humanities and social sciences was tested separately in this research to further verify the stability of the model and the reliability of the conclusion.

\section{Empirical Analysis}

\subsection{Descriptive Analysis}

From the basic situation of data acquisition, a total of 13,331 international scientific research collaboration papers were published by 42 China's world-class universities from 2015 to 2019, among which the average papers were cited 7.62 times, the average discipline standardization impact of each paper was 1.72, and the sum of the average author's $\mathrm{H}$ index reached 60.95 . The average number of authors per paper is 4.67 , involving 2.32 countries, of which the average number of institutions from developed countries is 1.18. Among the cooperative universities, an average of 3.32 institutions were involved in each paper, with an average of 0.50 institutions from world-class universities. The overall situation shows that China's universities have a high level of international collaboration research in humanities and social sciences, with FWCI exceeding the global average. Moreover, the authors of collaboration papers have a great impact on scientific research and a wide range of international collaboration, with each paper involving an average of two countries, and at least one of them is a developed country. See Table 2 below for details.

It is worth noting that in international scientific research collaboration, the proportion of international collaboration in humanities and social sciences led by China's world-class universities is low, accounting for only $42.61 \%$.

Table 2. Descriptive analysis of data.

\begin{tabular}{|c|c|c|c|c|c|}
\hline \multirow{2}{*}{ Variable } & \multirow{2}{*}{ Quantity } & \multicolumn{4}{|c|}{ Descriptive Statistic } \\
\hline & & Minimum & Maximum & Mean Value & Standard Deviation \\
\hline Citations & 13,331 & 0 & 641 & 7.62 & 17.59 \\
\hline Field-Weighted Citation Impact (FWCI) & 13,331 & 0 & 120.23 & 1.72 & 3.59 \\
\hline H index & 13,331 & 0 & 15,690 & 60.95 & 151.26 \\
\hline Number of top 100 institutions to which participants belong & 13,331 & 0 & 25 & 0.50 & 0.84 \\
\hline Number of authors & 13,331 & 2 & 301 & 4.67 & 4.78 \\
\hline Number of countries to which participants belong & 13,331 & 1 & 42 & 2.32 & 1.32 \\
\hline Number of participants involved in developed countries & 13,331 & 0 & 24 & 1.18 & 0.91 \\
\hline Number of institutions to which participants belong & 13,331 & 2 & 99 & 3.32 & 2.82 \\
\hline
\end{tabular}

\subsection{Variable Correlation and Multicollinearity Test}

In this research, the correlation test between the variables was preliminarily conducted to better explore the relationship between the respective variables and the dependent variables, and the test results in Table 3 found that there was a significant correlation between all variables.

According to the pre-analysis of the data, there is a significant correlation among the factors affecting the dependent variable, which will lead to a multicollinearity problem to a certain extent. Therefore, the multicollinearity test was carried out in this research, and the analysis results in Table 4 showed that the VIF values of the respective variables were all less than 10 , indicating that there was no multicollinearity problem between the variables in the regression model, and the regression equation was reliable. 
Table 3. Correlation test.

\begin{tabular}{|c|c|c|c|c|c|c|c|c|}
\hline Variable & Citations & $\begin{array}{c}\text { Field- } \\
\text { Weighted } \\
\text { Citation } \\
\text { Impact } \\
\text { (FWCI) }\end{array}$ & $\begin{array}{c}\mathbf{H} \\
\text { Index }\end{array}$ & $\begin{array}{c}\text { Number of Top } \\
100 \text { Institutions } \\
\text { to Which } \\
\text { Participants } \\
\text { Belong }\end{array}$ & $\begin{array}{c}\text { Number } \\
\text { of } \\
\text { Authors }\end{array}$ & $\begin{array}{l}\text { Number of } \\
\text { Countries to } \\
\text { Which } \\
\text { Participants } \\
\text { Belong }\end{array}$ & $\begin{array}{c}\text { Number of } \\
\text { Participants } \\
\text { Involved in } \\
\text { Developed } \\
\text { Countries }\end{array}$ & $\begin{array}{c}\text { Number of } \\
\text { Institutions } \\
\text { the } \\
\text { Participants } \\
\text { Belong to }\end{array}$ \\
\hline Citations & 1 & & & & & & & \\
\hline $\begin{array}{c}\text { Field-Weighted } \\
\text { Citation Impact (FWCI) }\end{array}$ & $0.67^{* * *}$ & 1 & & & & & & \\
\hline H index & $0.15^{* * *}$ & $0.12 * * *$ & 1 & & & & & \\
\hline $\begin{array}{l}\text { Number of top } 100 \\
\text { institutions to which } \\
\text { participants belong }\end{array}$ & $0.12 * * *$ & $0.12 * * *$ & $0.44^{* * *}$ & 1 & & & & \\
\hline Number of authors & $0.12 * * *$ & $0.11^{* * *}$ & $0.80^{* * *}$ & $0.52 * * *$ & 1 & & & \\
\hline $\begin{array}{l}\text { Number of countries to } \\
\text { which participants } \\
\text { belong }\end{array}$ & $0.11^{* * *}$ & $0.13^{* * *}$ & $0.39^{* * *}$ & $0.43^{* * *}$ & $0.62^{* * *}$ & 1 & & \\
\hline $\begin{array}{l}\text { Number of participants } \\
\text { involved in developed } \\
\text { countries }\end{array}$ & $0.13^{* * *}$ & $0.14^{* * *}$ & $0.42^{* * *}$ & $0.49^{* * *}$ & $0.59^{* * *}$ & $0.89 * * *$ & 1 & \\
\hline $\begin{array}{l}\text { Number of institutions } \\
\text { to which participants } \\
\text { belong }\end{array}$ & $0.15^{* * *}$ & $0.15^{* * *}$ & $0.62^{* * *}$ & $0.58^{* * *}$ & $0.81^{* * *}$ & $0.77^{* * *}$ & $0.74^{* * *}$ & 1 \\
\hline
\end{tabular}

Table 4. Multicollinearity test.

\begin{tabular}{ccc}
\hline Variable & VIF & 1/VIF \\
\hline H index & 2.1 & 0.48 \\
Number of top 100 institutions to which participants belong & 1.49 & 0.67 \\
Number of authors & 4.68 & 0.21 \\
Number of countries to which participants belong & 9 & 0.11 \\
Number of participants involved in developed countries & 7.26 & 0.14 \\
Number of institutions to which participants belong & 5.97 & 0.17 \\
\hline
\end{tabular}

4.3. Analysis of the Impact of International Research Collaboration Papers Based on the Level of Discipline Standardization

In this research, OLS regression was used to process the data by stata 14.0. The heteroscedasticity test results of the regression equation showed that the random error term in the overall regression function did not satisfy the hypothesis of homovariance, so Robust (robust standard error) analysis was adopted in this research. Since the number of authors, the number of institutions, and the number of countries to which participants belong are scale variables, which tend to show an inverted U-shaped relationship with the explained variables, the analysis results were included in their quadratic terms for interpretation. At the same time, the regression results of social sciences and humanities were presented in this research to further verify the stability of the regression equation. The specific results are shown in Table 5 below.

Hypothesis 1 predicts that the research impact of international collaboration papers can be significantly enhanced by the overall impact of the authors. As can be seen from the research results of Model 1, under the premise of other conditions remaining unchanged, the FWCI level of international collaboration papers increases by 0.011 units when the total $\mathrm{H}$ index of authors of international research collaboration papers increases by 1 unit. This hypothesis provides statistical support at the significance level of $1 \%$, indicating that Hypothesis 1 is valid. 
Table 5. Regression analysis results (dependent variable is the impact of discipline standardization).

\begin{tabular}{|c|c|c|c|}
\hline Variable & $\begin{array}{c}\text { Model 1 } \\
\text { (Humanities and Social Sciences) }\end{array}$ & $\begin{array}{c}\text { Model } 2 \\
\text { (Social Sciences) }\end{array}$ & $\begin{array}{c}\text { Model 3 } \\
\text { (Humanities) }\end{array}$ \\
\hline H index & $0.011^{* * *}$ & $0.011^{* * *}$ & $0.014^{* * *}$ \\
\hline Number of authors & $-0.037 *$ & $-0.042 * *$ & $-0.271^{* * *}$ \\
\hline Number of institutions to which participants belong & 0.045 & 0.059 & -0.007 \\
\hline Number of top 100 institutions to which participants belong & $0.165 * * *$ & $0.172 * * *$ & 0.257 \\
\hline Number of countries to which participants belong & $0.169 *$ & 0.14 & $0.677 *$ \\
\hline Number of participants involved in developed countries & 0.061 & 0.058 & -0.419 \\
\hline Are domestic universities the signature unit of the first author? & $0.146^{* * *}$ & $0.15^{* * *}$ & 0.12 \\
\hline Quadratic term of the number of authors & $-0.002 * * *$ & $-0.002 * * *$ & 0.006 \\
\hline Quadratic term of the number of participating institutions & 0.001 & 0.001 & 0.001 \\
\hline Number of countries to which participants belong & $-0.006^{* *}$ & -0.005 & $-0.025 * * *$ \\
\hline Cons & $0.589 * * *$ & $0.611 * * *$ & 1.299 \\
\hline $\mathrm{N}$ & 13,331 & 12341 & 2353 \\
\hline $\mathrm{R} 2$ & 0.067 & 0.071 & 0.024 \\
\hline $\mathrm{F}$ & 7.629 & 7.273 & 165.392 \\
\hline
\end{tabular}

Note: “***" means a significance level of $1 \%$, "**” indicates a significance level of $5 \%$, and “*” refers to a significance level of $10 \%$.

Hypothesis 2 predicts that the research impact of international collaboration papers can be significantly enhanced by the number of authors participating in international scientific research collaboration papers.

As can be seen from the research results of Model 1, the number of the authors of the paper and their quadratic coefficients have a significant impact on the impact of international collaboration papers. However, according to the calculation of their quadratic coefficients and symmetry axis, the overall impact shows a decreasing trend in the interval (the number of authors is greater than 0); that is, under the premise of other conditions remain unchanged, the more the number of authors, the less the impact of international scientific research collaboration papers, indicating that Hypothesis 2 is not valid.

Hypothesis 3 predicts that the more institutions are participating in international collaboration, the greater the impact of international collaboration papers. As can be seen from the research conclusion of Model 1, the institutions the participants belong to and their quadratic terms have no significant impact on the international collaboration papers, indicating that Hypothesis 3 is not valid.

Hypothesis 4 predicts that the greater the number of countries participating in international collaboration, the greater the impact of research papers on international collaboration. As can be seen from the results of Model 1, the number of countries to which participants belong and their quadratic terms can significantly affect the impact of scientific research. However, according to the calculation of their quadratic coefficients and symmetry axis, the overall impact shows an inverted U-shaped impact within the interval (the number of countries is greater than 0 ); that is, when the number of national collaboration is less than 14 , the more countries participating in the collaboration, the greater the impact of scientific research papers, and when the number of international collaboration is greater than 13 , the impact will decrease. The research results show that Hypothesis 4 is not valid.

Hypothesis 5 predicts that the greater the number of teachers from high-level universities participating in international scientific research collaboration papers, the greater the impact of scientific research collaboration papers. As can be seen from the research results of Model 1, under the premise of other conditions remain unchanged, the FWCI of scientific research papers can increase by 0.169 units for each additional world-class university participating in international research collaboration. This hypothesis provides statistical support at the significance level of $1 \%$, indicating that Hypothesis 5 is valid.

Hypothesis 6 predicts that the greater the number of developed countries participating in international research collaboration papers, the greater the impact of research collaboration papers. As can be seen from the research results of Model 1, under the premise of other conditions remaining unchanged, the number of participation backgrounds from developed countries has no effect on the promotion of scientific research impact, indicating that Hypothesis 6 is not valid. According to the results of overall regression analysis, Hy- 
pothesis 1 and Hypothesis 5 are valid, while Hypothesis 2, Hypothesis 3, Hypothesis 4, and Hypothesis 6 are not. The verification results of Hypothesis 2 show that the increase of the number of people participating in international collaboration will significantly reduce the impact of scientific research collaboration papers, and the verification results of Hypothesis 4 indicate that the diversity of national background of international collaboration papers has an inverted U-shaped impact on the impact of scientific research papers. It is noteworthy that the regression results of control variables show that the impact of international scientific research collaboration papers led by China is higher.

In this research, Robust (Robust standard error) analysis of OLS was carried out for social sciences and humanities, respectively to further explore the factors affecting the impact of research papers in social sciences and humanities and verify the stability of hypotheses of this model. As can be seen from the regression results of model 2 and model 3, the research conclusions are basically consistent with the overall regression results. The difference lies in: for international research collaboration papers in social sciences, the number of countries to which participants belong has no significant effect, but the number of high-level institutions involved has a significant effect; for the humanities, the impact of whether participants belong to high-level institutions is negligible, but the number of countries involved has a significant impact.

\section{Discussion and Conclusions}

International scientific research collaboration in the humanities and social sciences will contribute to the better participation of countries in the world in global governance and the promotion of international cultural exchanges. In this research, the international research collaboration papers on humanities and social sciences in world-class universities are analyzed, and the influencing factors of promoting international research collaboration papers are explored. Based on the analysis results of 13,331 international research collaboration papers published by 42 universities, the following conclusions can be drawn.

Firstly, the key to enhance the impact of international research collaboration papers lies not in the scale of international collaboration, but in whether high-quality collaborators are selected. It can be seen from the research conclusion that the higher the overall $\mathrm{H}$ index level of the paper participants, the more scholars involved in high-level universities, and the higher the overall scientific research impact of the paper. This indicates that in international collaboration, it is crucial to select authors who are active in the research community and who can produce high-impact achievements. The research conclusion also shows that the impact of discipline standardization of a scientific research paper will be significantly reduced by the excessive number of participants in an international research collaboration paper. This conclusion is consistent with the existing research conclusions in the field of humanities: there is no significant advantage in the quality of papers published in international collaboration with the increase of the number of participants (Puuska et al. 2014). It should also be noted that many collaboration papers do not get citations and their FWCI values are zero, which means the international collaboration papers are not recognized by others. In this context, domestic researchers should cooperate with influential scholars in the process of international collaboration, instead of passively joining in or seeking more participants.

Secondly, more researchers with different backgrounds, especially those from highlevel universities, need to be recruited to participate in research to enhance the impact of international collaboration in scientific research. It has been thought that diversification of research teams is more beneficial to scientific research innovation than homogenization (De Dreu and West 2001). The conclusion of this research also shows that the more researchers in high-level universities are involved in international scientific research collaboration, the greater their scientific research impact. To explain this, the diversity of team members' backgrounds provides more research perspectives to analyze the problem in different ways. In addition, researchers from high-level universities are often supported by 
more abundant research resources, which is more conducive to international exchanges and investigations, thus enhancing the impact of research.

Thirdly, the scope of international collaboration should be expanded. Whether researchers are from developed countries or not, the impact of research papers can be effectively enhanced by attracting more international scholars to participate in the humanities and social sciences research. In the research conclusion, the number of countries involved in scientific research papers and the impact of scientific research papers present an inverted U-shaped relationship, but the calculation results based on the symmetry axis show that the proportion of samples in the decreasing interval is only $0.3 \%$. It can therefore be judged that in the field of humanities and social sciences, the wider the scope of international scientific research collaboration, the greater the impact of scientific research collaboration. This may be due to the fact that large-scale international humanities and social science research can be transformed into effective policy results and widely disseminated in the international scope.

Fourthly, compared with social sciences, research participants from high-level institutions have little impact, but have higher requirements on the internationalization of research collaboration. This may be because the research of humanities is not highly correlated with the material research support provided by universities, but more closely correlated with the research environment and research characteristics of the country in this field of humanities. More countries participating in the discussion and research can ensure the acceptability of the research conclusions, thus enhancing the impact of international collaboration papers on scientific research.

Fifthly, international research collaboration papers led by world-class universities are more influential, which suggests that researchers from high-level universities in China should actively participate in global international research collaboration. China, as the largest developing country in the world, plays an increasingly important role in the process of globalization and international affairs. Under this background, positive measures should be taken by Chinese researchers, especially social scientists, to expand their international horizons, actively participate in global governance, and play a role in promoting the construction of a community with a shared future for mankind. In this research, China's world-class universities are taken as the object to explore relevant factors that can increase the impact of international collaboration papers in the field of humanities and social sciences. The results show that the scientific research level of collaborators, the number of participants, the strength of the institution, and the degree of international collaboration should be considered to enhance the impact of international collaborative papers. On the one hand, the relevant factors affecting the impact of research papers are explored in this research, and causal inferences are made on the relevant variables to verify several hypotheses made by predecessors in the international collaboration research of universities. On the other hand, focusing on the field of humanities and social sciences and exploring feasible ways to improve the impact of humanities and social sciences can provide references for China's humanities and social sciences to better participate in global governance research and promote international cultural exchanges.

However, it should be noticed that the findings of the research indicate that attention should be paid to collaborators' research reputation and the level of their institutions. During the process, researchers should also give comprehensive judgment of the research level of the potential co-author. According to Merton's theory, the Matthew effect exists in the scientific community, which will lead to the unfairness of the recognition of achievements (Merton 1968). The citation frequency of high-profile scholars is always much higher than that of unknown scholars, who are still able to do valuable research. As a result, it would also bring great advantage to cooperate with those scholars who are not famous at present.

Nevertheless, the following shortcomings still exist in this research: Firstly, since the research object was only limited to China's world-class universities and the time period of the collaboration papers ranged from 2015 to 2019, some valuable papers may be not cited during the period, although since FWCI was used to fix the problem, it would also bring 
bias to the conclusion; secondly, in the process of variable selection of this research, the quantitative characteristics of domestic and international participants in the author-level data are not separated due to the requirements of data processing technology. Thirdly, there are also many international collaboration articles that are not contained in the database, which might also influence the generality of the conclusion. In future research, such problems need to be responded to and resolved.

Author Contributions: Conceptualization, C.W. and Z.C.; methodology, Z.C.; software, X.L.; validation, X.X., Z.C. and X.L.; formal analysis, Z.C.; investigation, X.X.; resources, X.L.; data curation, X.L.; writing—original draft preparation, Z.C.; writing—review and editing, X.X., C.W.; visualization, X.X.; supervision, C.W.; project administration, C.W. All authors have read and agreed to the published version of the manuscript.

Funding: This research received no external funding.

Institutional Review Board Statement: Not applicable.

Informed Consent Statement: Not applicable.

Data Availability Statement: Data sharing not applicable.

Conflicts of Interest: The authors declare no conflict of interest.

\section{References}

Abramo, Giovanni, Ciriaco Andrea D'Angeloa, and Marco Solazzia. 2011a. Are researchers that collaborate more at the international level top performers? an investigation on the italian university system. Journal of Informetrics 5: 204-13. [CrossRef]

Abramo, Giovanni, Ciriaco Andrea D'Angeloa, and Marco Solazzia. 2011b. The relationship between scientists' research performance and the degree of internationalization of their research. Scientometrics 86: 629-43. [CrossRef]

Adams, James D., Grant C. Black, J. Roger Clemmons, and Paula E. Stephan. 2005. Scientific Teams and Institution Collaborations: Evidence from U.S. Universities, 1981-1999. Rochester: Social Science Electronic Publishing.

Adams, Jonathan, Karen Gurney, and Stuart Marshall. 2007. Patterns of International Collaboration for the UK and Leading Partners. Available online: https:/ / www.semanticscholar.org/paper/Patterns-of-International-Collaboration-for-the-UK-AdamsGurney/44c3adfa0a6670c3dcd979e1bed18ed93632acb6 (accessed on 1 February 2021).

Avkiran, Necmi Kemal. 1997. Scientific collaboration in finance does not lead to better quality research. Scientometrics 39: 173-84. [CrossRef]

Barjak, Franz, and Simon Robinson. 2008. International collaboration, mobility and team diversity in the life sciences: Impact on research performance. Social Geography 3: 23-26. [CrossRef]

Bordons, Maria, Isabel Gomez, M. Teresa Fernandez, M. Angeles Zulueta, and Aida Mendez. 1996. Local, Domestic and International Scientific Collaboration in Biomedical Research. Scientometrics 37: 279-95. [CrossRef]

Bordons, María, Borja González-Albo, Javier Aparicio, and Luz Moreno. 2015. The influence of R\&D intensity of countries on the impact of international collaborative research: Evidence from Spain. Scientometrics 102: 1-16.

Carayol, Nicolas, and Mireille Matt. 2004. The exploitation of complementarities in scientific production process at the laboratory level. Technovation 24: 455-65. [CrossRef]

Chang, Han-Wen, and Mu-Hsuan Huang. 2016. The effects of research resources on international collaboration in the astronomy community. Journal of the Association for Information Science and Technology 67: 2489-510. [CrossRef]

Chinchilla-Rodríguez, Zaida, Cassidy R. Sugimoto, and Vincent Larivière. 2019. Follow the leader: On the relationship between leadership and scholarly impact in international collaborations. PLoS ONE 14: e0218309. [CrossRef]

Chinchilla-Rodríguez, Zaida, Maria Benavent-Pérez, and Félix de Moya-Anegón. 2012. International collaboration in Medical Research in Latin America and the Caribbean (2003-2007). Journal of the American Society for Information Science and Technology 63: 2223-38. [CrossRef]

De Dreu, Carsten K. W., and Michael Alun West. 2001. Minority Dissent and Team Innovation: The Importance of Participation in Decision Making. Journal of Applied Psychology 86: 1191-201. [CrossRef] [PubMed]

Gazni, Ali, and Fereshteh Didegah. 2011. Investigating different types of research collaboration and citation impact: A case study of Harvard University's publications. Scientometrics 87: 251-65. [CrossRef]

Glänzel, Wolfgang, and András P. Schubert. 2001. Double effort = Double impact? A critical view at international co-authorship in chemistry. Scientometrics 50: 199-214. [CrossRef]

Glänzel, Wolfgang, and Cornelius de Lange. 2002. A distributional approach to multinationality measures of international scientific collaboration. Scientometrics 54: 75-89. [CrossRef]

Guerrero Bote, Vicente P., Carlos Olmeda-Gómez, and Félix de Moya-Anegón. 2013. Quantifying the benefits of international scientific collaboration. Journal of the American Society for Information Science E Technology 64: 392-404. 
Guo, Shesen, Ganzhou Zhang, and Yufei Guo. 2015. Social Network Analysis of 50 Years of International Collaboration in the Research of Educational Technology. Journal of Educational Computing Research. [CrossRef]

He, Tianwei. 2009. Scientometric Indications of Chinese SCI Papers with International. Bulletin of National Natural Science Foundation of China 23: 93-97.

Hsiehchen, David, Magdalena Espinoza, and Antony Hsieh. 2018. Evolution of collaboration and optimization of impact: Selforganization in multinational research. Scientometric 117: 391-407. [CrossRef]

Jeong, Seongkyoon, Jae Young Choi, and Jaeyun Kim. 2011. The determinants of research collaboration modes: Exploring the effects of research and researcher characteristics on co-authorship. Scientometrics 89: 967-83. [CrossRef]

Katz, J. Sylvan, and Ben R. Martin. 1997. What is research collaboration? Research Policy 26: 1-18. [CrossRef]

Khor, Khiam Aik, and Ligen Yu. 2016. Influence of international co-authorship on the research citation impact of young universities. Scientometrics 107: 1095-110. [CrossRef]

Kwiek, Marek. 2020. Internationalists and locals: International research collaboration in a resource-poor system. Scientometrics 124: 57-105. [CrossRef]

Kyvik, Svein, and Ingvild Reymert. 2017. Research collaboration in groups and networks: Differences across academic fields. Scientometrics 113: 951-67. [CrossRef] [PubMed]

Lancho-Barrantes, Bárbara S., Vicente P. Guerrero-Bote, and Felix de Moya-Anegon. 2013. Citation increments between collaborating countries. Scientometrics 94: 817-31.

Leydesdorff, Loet, Lutz Bornmann, and Caroline S. Wagner. 2017. The relative influences of government funding and international collaboration on citation impact. Journal of the Association for Information Science and Technology 70: 198-201. [CrossRef] [PubMed]

Merton, Robert K. 1968. The Matthew Effect in Science, The reward and communication systems of science are considered. Science 159: 56-63. [CrossRef]

Narin, Francis, Kimberly A. Stevens, and Edith S. Whitlow. 1991. Scientific co-operation in Europe and the citation of multinationally authored papers. Scientometrics 21: 313-23. [CrossRef]

Nguyen, Tuan V., Thao P. Ho-Le, and Ut V. Le. 2017. International collaboration in scientific research in Vietnam: An analysis of patterns and impact. Scientometrics 110: 1035-51. [CrossRef]

Parker, Jan. 2007. Priorities for the future of Humanities in Europe: What can humanities contribute? Social Sciences Abroad 4: 98-100.

Payumo, Jane, Taurean Sutton, Derek Brown, Dan Nordquist, Marc Evans, Danna Moore, and Prema Arasu. 2017. Input-output analysis of international research collaborations: A case study of five US universities. Scientometrics: An International Journal for All Quantitative Aspects of the Science of Science Policy 111: 1657-71. [CrossRef]

Prakasan, E. R., Lalit Mohan, Priya Girap, Ganesh Surwase, B. S. Kademani, and K. Bhanumurthy. 2014. Scientometric facts on international collaborative Indian publications. Current Science 106: 166-69.

Price, D., J. G. Sone, and Z. F. Dai. 1982. Small Science and Big Science. Singapore: World Science Publishing.

Puuska, Hanna-Mari, Reetta Muhonen, and Yrjö Leino. 2014. International and domestic co-publishing and their citation impact in different disciplines. Scientometrics 98: 823-39. [CrossRef]

Qiu, J. P., and Q. Zeng. 2013. Can international cooperation improve the influence of scientific research-Taking computer science as an example. Information Studies: Theory \& Application 36: 1-5.

Quan, Wei, Philippe Mongeon, Maxime Sainte-Marie, Rongying Zhao, and Vincent Larivière. 2019. On the development of China's leadership in international collaborations. Scientometrics 120: 707-21. [CrossRef]

Roosa, Leimu, and Koricheva Julia. 2005. Does scientific collaboration increase the impact of ecological articles? Bioence 5: 438-43.

Suárez-Balseiro, Carlos, Carlos García-Zorita, and Elías Sanz-Casado. 2009. Multi-authorship and its impact on the visibility of research from Puerto Rico. Information Processing \& Management 45: 469-76.

Sud, Pardeep, and Mike Thelwall. 2016. Not all international collaboration is beneficial: The Mendeley readership and citation impact of biochemical research collaboration. Journal of the Association for Information Science and Technology 67: 1849-57. [CrossRef]

Van Raan, Anthony. 1998. The influence of international collaboration on the impact of research results. Scientometrics 42: 423-28. [CrossRef]

Wagner, Caroline S., Travis A. Whetsell, and Satyam Mukherjee. 2019. International research collaboration: Novelty, conventionality, and atypicality in knowledge recombination. Research Policy 48: 1260-70. [CrossRef]

Wood, John, James Walter, and Kerry Carrington. 2007. The importance of social science to government. Social Sciences Abroad 4: 97-98.

Yao, Jia Wen, Tie-Wu Jia, and Xiao-Nong Zhou. 2013. Assessing the correlation between international collaboration and academic influence in parasitic diseases: A case study of National Institute of Parasitic Diseases, Chinese Center for Disease Control and Prevention. Chinese Journal of Schistosomiasis Control 25: 367-74.

Ye, W. P., W. Y. Liang, and Y. M. Hu. 2017. How far is C9 University from the world first class University. Education Research 38 : 53-66. 